\title{
Supply Chain Governance of Agricultural Products under Big Data Platform Based on Blockchain Technology
}

\author{
Wei Guo $\left.{ }^{1}\right)^{1}$ and Kai Yao \\ ${ }^{1}$ Department of Business Administration, Anhui Business College, Wuhu 241002, Anhui, China \\ ${ }^{2}$ School of Management, Fudan University, Shanghai 200433, China \\ Correspondence should be addressed to Wei Guo; guowei@abc.edu.cn
}

Received 25 October 2021; Revised 15 November 2021; Accepted 23 November 2021; Published 6 January 2022

Academic Editor: Le Sun

Copyright (C) 2022 Wei Guo and Kai Yao. This is an open access article distributed under the Creative Commons Attribution License, which permits unrestricted use, distribution, and reproduction in any medium, provided the original work is properly cited.

\begin{abstract}
The present work serves to improve the stable cooperation relationship among subjects of supply chain such as enterprises, farmers, intermediary organizations, and retailers and enhance the governance and optimization of agricultural product supply chain, thus strengthening the competitiveness of China's agricultural industry. The supply chain governance of agricultural products is taken as the research object. Initially, the stabilities of two supply chain organization modes, "company and farmer" and "company, intermediary organization and farmer," are analyzed by static game analysis. Then, based on the above analysis and the characteristics of blockchain institutional technology, a detailed analyzation is made on the mechanism of supply chain of agricultural products governance based on blockchain technology. Finally, the functional framework of agricultural supply chain governance is designed based on the basic framework of blockchain technology, and analyzation is made on the trust mechanism and contract mechanism of agricultural supply chain governance based on blockchain technology. The research results show that problems such as information and cognitive constraints in agricultural supply chain governance cannot be completely solved only through the evolution of blockchain organizational structure and the supply of governance mechanism, and speculative behavior will still appear. Optimizing the governance of supply chain of agricultural products based on blockchain technology can realize the transformation of its governance scenario. Meanwhile, the blockchain technologies such as deintermediation, demistrust, and intelligent contract play an important role in the process of agricultural supply chain governance, which can make it change in many aspects such as organization mode, application operation, and governance mechanism. The rapid development of new generation information technologies such as blockchain, the Internet of Things, and computer technology makes it possible to comprehensively digitize economic activities such as production and transaction in the supply chain of agricultural products. The present work combines the technical logic of blockchain digital governance with the institutional logic of agricultural product supply chain governance and tries to solve the instability problems caused by imperfect organization, lack of trust, and incomplete contract in agricultural product supply chain governance with the characteristics of blockchain such as deintermediation, demistrust, and intelligent contract.
\end{abstract}

\section{Introduction}

Under the rapid development of free market economy, in order to realize the modernization of China's agricultural field, society must keep up with the pace of reform and opening up. With the constant industrialization of agriculture, the agricultural economic form has changed to some extent. New forms of agricultural products supply chain emerge such as strategic alliance and cooperative production. Under the organization modes of "company and farmer" and "company, intermediary organization and farmer," the supply chain of agricultural products is constantly developing and growing $[1,2]$. Establishing a stable cooperative relationship among the participants in the agricultural supply chain and strengthening the governance of the agricultural supply chain can effectively improve the competitive advantage of China's agriculture. In recent years, a variety of agricultural products supply chain models, 
such as "farmers and companies," "family farms and companies," and "farmers, supermarkets, and rural cooperatives" have emerged constantly, and the participants are also growing [3]. On the whole, through the governance and optimization of supply chain of agricultural products, the cooperative relationship in supply chain of agricultural products has become relatively stable. Its organizational structure has gradually changed from loose to tight. However, there are still some problems to be solved in China's agricultural supply chain for a long time, such as the difficulty in ensuring the quality of agricultural products, the high default rate when farmers and companies cooperate, and the difficulty in reaching long-term cooperative relations [4-6].

By consulting relevant references, results turn out that many researchers attribute the change of the relationship of supply chain of agricultural products to the change of system. Based on the relevant theories under the new system, study and discussion are made on the formation and evolution of supply chain of agricultural products. On the governance of agricultural supply chain, some relevant scholars have compared the governance mechanism and transaction relationship in different agricultural products circulation channels through actual case analysis. The research results show that the long-term transaction relationship of "order industry" has the highest performance level, which verifies that trust relationship is beneficial to improving industry performance [7]. In the follow-up development process, some researchers also used case analysis and model empirical method to analyze the causal relationship of the relationship governance elements between vegetable growers and companies. The results show that there are the two following causal chains during the transaction between vegetable growers and companies. "Farmers' perception of enterprise behavior determines whether farmers trust the enterprise, which in turn determines the cooperative relationship between farmers and companies." "Farmers' trust in companies will affect the degree of cooperation between farmers and companies, which in turn determines the certainty of farmers' transactions" [8].

At present, there are many researches on the governance optimization of supply chain of agricultural products globally, but most of them are focused on how to alleviate the effectiveness of opportunistic risks through the optimization of governance models and mechanisms, while there are relatively few researches on the governance optimization of supply chain of agricultural products based on blockchain embedding. Therefore, based on blockchain digital governance technology, optimization is made on the governance of agricultural supply chain, and solutions are given for the unstable problems caused by low trust between companies and farmers and imperfect organization and management system based on the characteristics of blockchain, such as deintermediation, demistrust, and intelligent contract.

\section{Literature Review}

The research on the organization and governance of agricultural product supply chain mainly evolved from the research on agricultural industrial organization. Li and Zhang
(2021) [9] concluded that vertical integration of agricultural supply chains had a positive impact on the safety of agricultural products through the analysis of economic models. With the improvement of vertical integration of agricultural products supply chain, wholesalers and suppliers have improved the security of agricultural products, reduced the circulation cost of agricultural products, and decreased the sales price of agricultural products. To promote the close integration of agricultural product supply chain, Zhou and Metawea (2021) [10] proposed a computer simulation model of agricultural product supply chain based on multiagent system. Through a series of simulation experiments, detailed discussion was made on the evolution of the organizational structure of agricultural supply chain under different government regulations and its impact on the quality and safety of agricultural products. The simulation results revealed that the more long-term contracts between farmers and retailers, the more conducive to the improvement of the quality and safety of agricultural products, and the scholars put forward corresponding countermeasures and suggestions. Qiu (2017) [11] studied retailers' pricing and ordering strategies based on real-time value loss information of agricultural products. Considering the influence of technology application on the circulation of fresh agricultural products, the scholars constructed the profit model of two stages of fresh agricultural products supply chain and analyzed three key parameters. The results indicated that the upstream and downstream parts of the supply chain had the consistent investment interval of technology label cost; under certain conditions, upstream suppliers bore the cost of technical labels, and wholesale and retail prices were determined by incremental delivery.

By comparing the relevant literature, it can be found that, in terms of theoretical research, Chinese researchers still focus on the theory of new institutional economics. The research on transaction governance and relationship governance based on transaction cost economics has just started. The research on agricultural product supply chain from the perspective of transaction cost economics in foreign countries has been relatively mature, which is also more in-depth and detailed, and is gradually expanded to the combination of various theories.

\section{Methods}

\subsection{Blockchain Data Structure and Functional Framework of the Blockchain System}

3.1.1. Blockchain Data Structure. Figure 1 signifies the data structure of the blockchain system.

Figure 1 illustrates that the blockchain is composed of a block header and a block body, and the block header also includes a timestamp, a random number, a target hash, and a Merkle root. The Merkle root is generated by the data structure of Merkle tree and counted in the head of the block, of which the value is unique. The blocks are connected in time sequence to form a blockchain. Each blockchain is connected by the address information of the previous block in the block header, and each transaction can be recorded in 


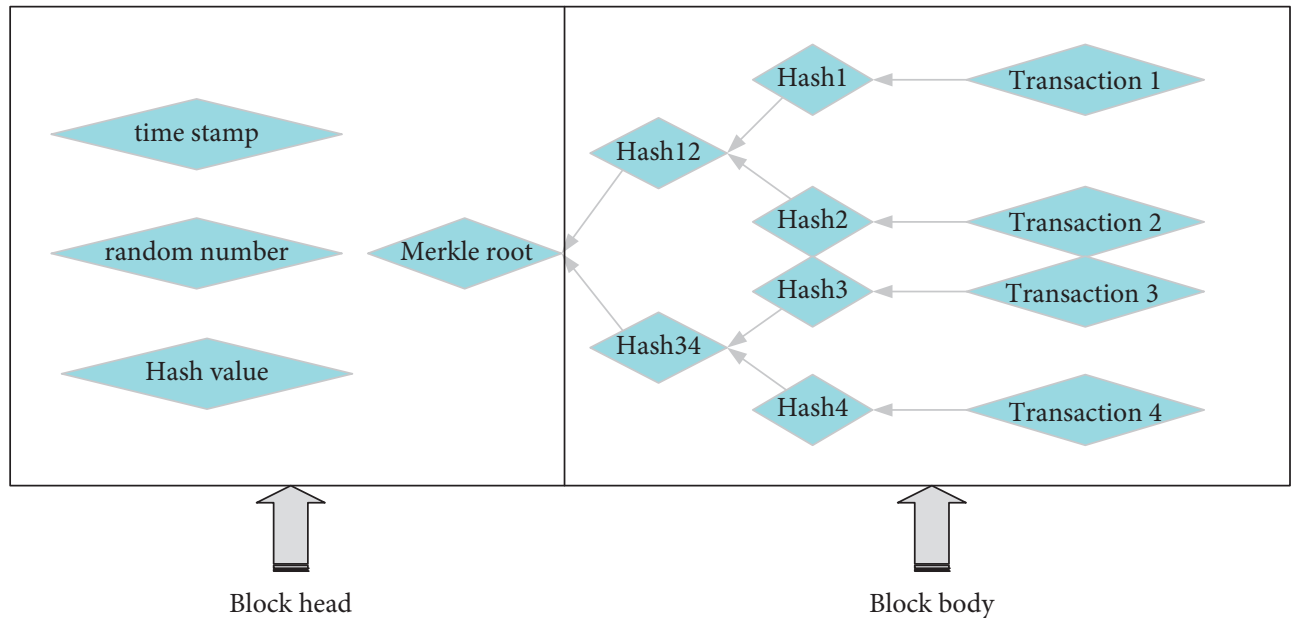

Figure 1: Blockchain data structure.

the block body by the Merkle tree structure key, finally forming a data chain with comprehensive transaction records $[12,13]$.

\subsubsection{Overall Functional Architecture of the Blockchain} System. With the continuous development of digital technology, the data structure of blockchain is constantly being updated. From the earliest distributed accounting system to Ethereum to the current alliance chain, it can be found that blockchain is constantly being merged with digital technology. Although there are some differences in specific applications among different blockchains, their overall architectures are basically the same [14]. Figure 2 shows the overall functional framework of the system.

\subsection{Stability Analysis of Supply Chain of Agricultural Products under Different Organizational Modes}

3.2.1. Stability Game Analysis under the Organization Mode of "Company and Farmer". Under this mode, the company signs long-term contracts with farmers. Based on the "company and farmers" mode, it can not only solve the supply problem of raw materials for agricultural products but also increase the sales volume of farmers' agricultural products. However, there are some problems that need to be solved urgently, such as the low trust between companies and farmers, which leads to frequent defaults between both parties. In this mode, the game relationship between the two parties is very obvious, and the trust relationship between the two parties will directly affect the development of the company and farmers [15]. This problem will be analyzed in detail below. Before the concrete analysis, it is assumed that when farmers and companies conduct transactions, both parties of the transaction are rational transactions, the purpose of which is to enable them to obtain greater benefits. Before trading, the quantity of agricultural products traded by both parties has been stated in the contract, which is set as $V$, and the prices of agricultural products will fluctuate accordingly different market conditions. The prices of agricultural products in good and better market conditions are set as $P_{g}$ and $P_{b}$, respectively. The price in the purchase of agricultural products of farmers is set as $P_{f}$, the production cost of farmers in the production of agricultural products is expressed as $C_{1}$, and the logistics cost of companies is represented by $C_{2}$. Farmers will hand over the quantity $V$ of agricultural products to companies for processing and sales, and finally the money profits obtained by companies are referred to by $M$, where $P_{g}>P_{f}>P_{b}$. The probability of default by both parties and the amount of compensation to be paid after default are set as $R$ and $L$, respectively [16]. As the default of an enterprise in the transaction process will have a certain impact on the reputation of the enterprise, the loss brought by the subsequent development of the enterprise is set as $D$. When the market develops well, the benefits of both parties of the transaction are as shown in Figure 3 [17].

As Figure 3 displays, when the overall development of the market is good, companies will make greater profits by choosing to abide by the contract, while farmers will make their choices by comparing the benefits they have obtained under the conditions of abiding by the contract and breaching the contract. The situation arises as

$$
V P_{f}-C_{1}>V P_{g}-C_{1}-L r .
$$

Namely,

$$
L r>V\left(P_{g}-P_{f}\right) .
$$

In equations (1) and (2), $V$ expresses the amount of agricultural products; $P_{f}$ represents the order price of agricultural products; $C_{1}$ denotes the production cost of farmers; $P_{g}$ refers to the price of agricultural products when there is more benefit in the market; $L$ stands for the compensatory payment for breaching of contract; $r$ accords with the rate that compensatory payment will be paid.

Then, the farmers' profit from breach of contract is greater than that from keeping the contract. Hence, farmers will choose to default.

When the overall development of the market is poor, the benefits of both parties to the transaction are as shown in Figure 4. 


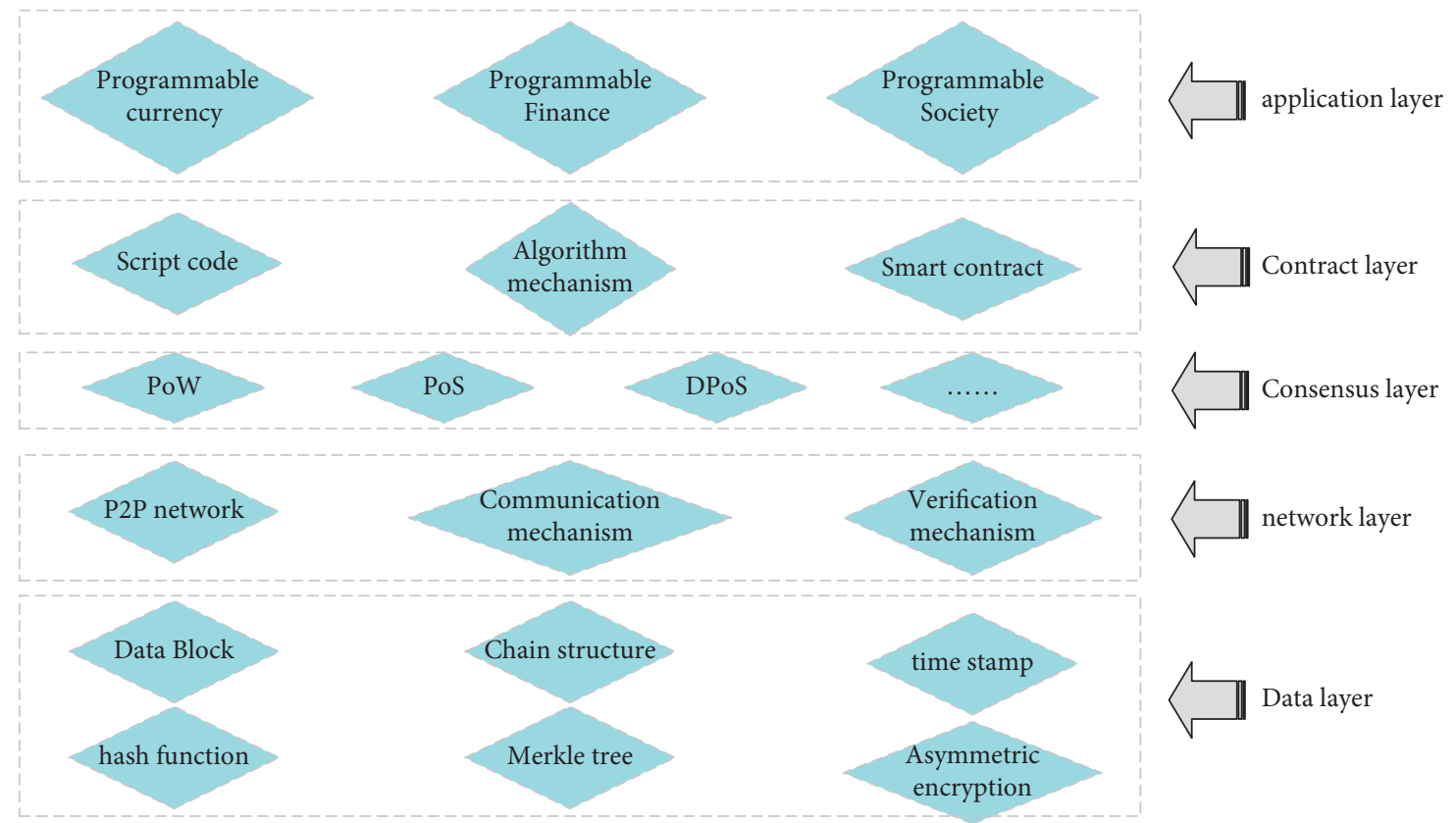

FIGURE 2: Overall functional framework of the blockchain system.

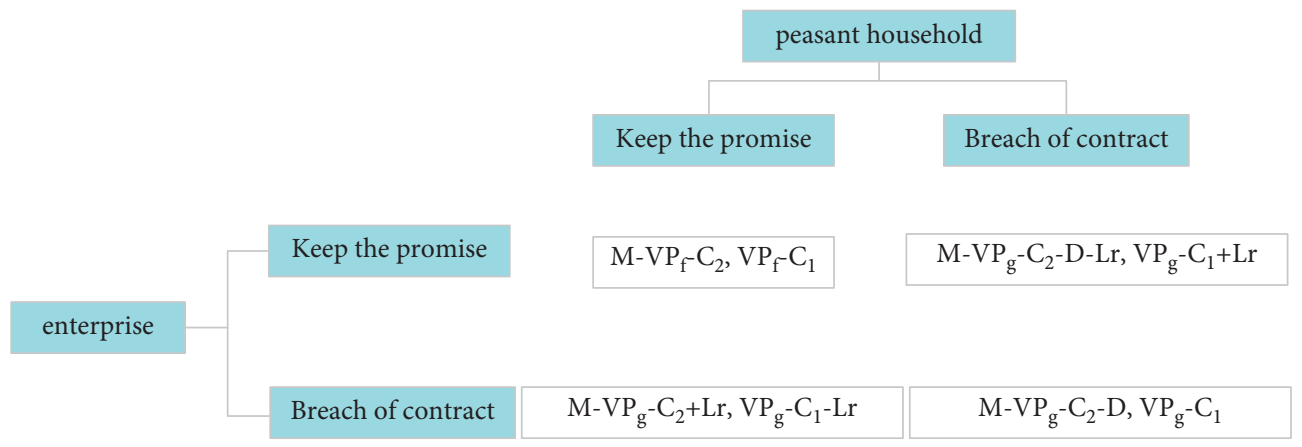

Figure 3: Benefits of both parties to the transaction when the market develops well.

As Figure 5 signifies, in the case of poor overall market development, farmers will make greater profits by choosing to keep the contract, while companies will make their choice by comparing the benefits obtained by keeping the contract and breaching the contract. The situation arises as follows:

$$
M-V P_{f}-C_{2}<M-V P_{b}-C_{2}+L r .
$$

Namely,

$$
V\left(P_{f}-P_{b}\right)>D+L r
$$

In equations (3) and (4), $M$ represents the gain of processing and selling $V$ agricultural products; $C_{2}$ expresses the logistic and production cost of enterprises; $P_{f}$ refers to the order price of agricultural products; $P_{b}$ refers to the price of agricultural products when there is less benefit in the market; $L$ stands for the compensatory payment for breach of contract; $r$ accords with the rate that compensatory payment will be paid; $D$ expresses the future discount losses, which will be led by the reputational losses suffered by enterprises, if they breach the contract.
Then, if the profit obtained by the enterprise's breach of contract is greater than the profit obtained by keeping the contract, the enterprise will choose to default.

The above analysis illustrates that the following aspects will influence the cooperative relationship between companies and farmers: first, the price fluctuation of agricultural products, and second, the cost of default, such as the probability of compensation and the amount of loss after default. The price fluctuation of agricultural products is mainly affected by the external environment, namely, market environment. From that perspective of default cost, because the number of farmers is large but the scale of their property is small, once the amount to be paid for breach of contract exceeds the scope of farmers' acceptance, farmers will think passively before participating in the supply chain organization, so the default amount should not be too large. Additionally, the value of compensation probability $r$ is mainly affected by transaction costs such as negotiation ability and litigation cost of both parties. However, because the price of agricultural products is relatively low, the value of agricultural products is often lower than the transaction 


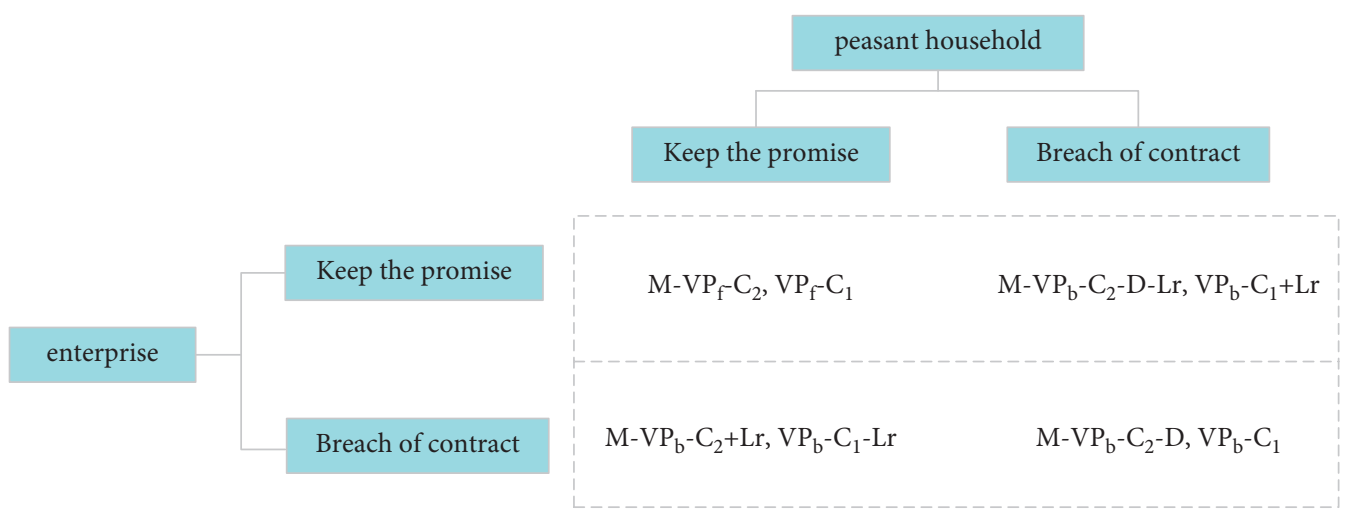

FIGURE 4: Income of both parties to the transaction subject when the market development is poor.

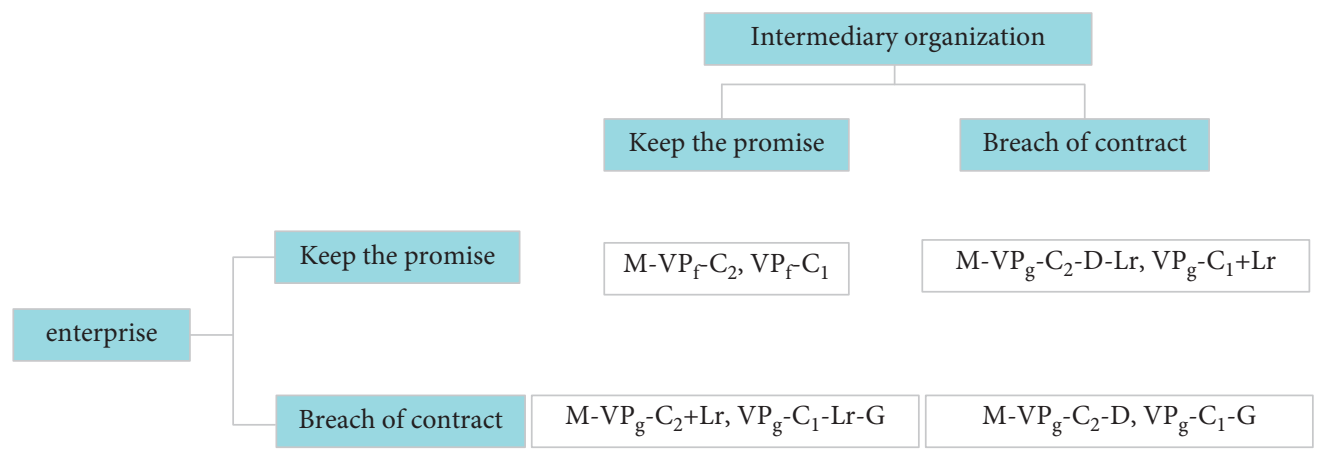

FIGURE 5: Benefits of companies and intermediary organizations when the market develops well.

execution cost, and both parties to the transaction will consider this factor and give up default during the transaction, so the probability of compensation is very low. Generally speaking, the stability of the organization mode of "farmers and companies" is relatively poor.

Time Impression Company, also known as Shaanxi Time Impression Electronic Commerce Co., Ltd., is engaged in online sales of agricultural and sideline products, storage, sales, and industrial information services of kiwifruit, as well as special products and dry fruit and fresh fruit acquisition and sales business. The operation mode of the enterprise is "company + farmer." It mainly cooperates with farmers in signing of planting acquisition contracts, where the enterprise puts forward a series of crop process requirements for farmers. Farmers grow products according to requirements of the enterprise, and the latter finally purchases products at market prices in the acquisition. The whole process from orchard to market is divided into several stages, and the scope of responsibility is delimited. Time Impression Company began to implement cooperation with farmers from 2010, mainly in the way of order acquisition during 2010-2011; in the way of order acquisition, technical training, and demonstration guidance during 2011-2013; and in the way of brand building, marketing, and integrated service system during 2014-2016.

3.2.2. Stability Game Analysis under the Organizational Mode of "Company, Intermediary Organization, and Farmer". The members of intermediary organizations in this mode are mostly local farmers, so the trust between intermediary organizations and farmers is high. Therefore, when analyzing this mode, the game relationship between farmers and intermediary organizations is ignored intentionally, and analyzation is made only on the game between companies and intermediary organizations [18].

Before the analysis, the following assumptions are made: in order to ensure that both parties can get the maximum benefits, both parties are rational in the transaction process. The number of agricultural products traded is set as $V$, the price of agricultural products is represented by $P_{f}$, and the prices of agricultural products are referred to by $P_{g}$ and $P_{b}$, when the market environment is good or bad, respectively, where $P_{g}>P_{f}>P_{b}$. The cost of the intermediary organization is $C_{1}$, and the cost of the enterprise in the transportation process is $C_{2}$. Farmers hand over $V$ quantity of agricultural products to the enterprise for processing and sales, and finally the money profit obtained by the enterprise is set as $M$, and the probability of default and the amount of compensation to be paid after default by both parties are set as $R$ and $L$, respectively. The losses caused to the development of companies or intermediary organizations are set as $D$ and $G$. Figure 5 indicates the benefits of both intermediary organizations and companies, when the overall market development is good [19].

As Figure 5 presents, when the overall development of the market is good, companies will make greater profits by choosing to abide by the contract, while intermediary organizations will make their choices by comparing the benefits obtained under the two situations of abiding by the 
contract and breaching the contract. The situation arises as equations (5) and (6) [20] show

$$
V P_{f}-C_{1}<V P_{g}-C_{1}-L r-G
$$

Namely,

$$
L r+G<V\left(P_{g}-P_{f}\right)
$$

In equations (5) and (6), $V$ refers to the amount of the agricultural products; $P_{f}$ indicates the price of agricultural products in the contract; $P_{g}$ represents the price of agricultural products when there is more benefit in the market; $C_{1}$ denotes the cost of the agricultural products purchased by intermediary organizations; $L$ expresses the compensatory payment for breach of contract; $r$ accords with the rate that compensatory payment will be paid; $G$ stands for the future discount losses, which will be led by the reputational losses suffered by intermediary organizations with certain size. The profit obtained by the intermediary organization's breach of contract is greater than the profit obtained by keeping the contract, so the enterprise will choose to default.

When the overall market development is poor, the benefits of both intermediary organizations and companies are presented in Figure 6.

Through the above analysis, the results show that the three following aspects will affect the cooperative relationship between companies and intermediary organizations: first, the price fluctuation range of agricultural products, second, the probability of compensation, and third, the loss caused by reputation damage after default to the future development of companies and intermediary organizations. The price fluctuation of agricultural products is mainly affected by the external environment. Compared with the organization mode of "company and farmer," the number of orders has been greatly increased due to the addition of intermediary organizations, and the order value has exceeded the cost required by default litigation, so the probability of winning compensation has been greatly improved.

\subsection{Mechanism Analysis on Governance Optimization of} Agricultural Products Supply Chain Based on Blockchain Technology. According to the analysis of " company and farmer" and "company, intermediary organization, and farmer" in Section 2 and the understanding of new institutional economics, it can be found that the agricultural products supply chain is constantly evolving in the way illustrated in Figure 7.

Institutional factors such as asset specificity, uncertainty, and transaction frequency play an important role in the organizational structure of agricultural products supply chain.

Figure 8 displays three important factors of governance of agricultural products supply chain based on blockchain data technology.

\subsubsection{Blockchain Optimizes the Network Organization} Structure of Supply Chain of Agricultural Products. Supply chain of agricultural products is a very complicated business system, and its main components include consumers, farmers, companies, supervision institutions, and cooperatives. Business entities not only have certain dynamics and randomness but also have certain constraints $[21,22]$. Therefore, certain requirements for the governance structure of blockchain are also put forward, so that it can be coupled with the governance structure of agricultural supply chain. Figure 9 signifies the specific structure.

As a decentralized and distributed database technology under collective maintenance, blockchain can save a lot of intermediary costs in reality. This peer-to-peer trading method with equal rights and obligations for each node eliminates the hierarchical relationship derived from the traditional central governance structure to the surrounding radiation. Therefore, the advantage of blockchain embedding in traditional organizations is to guide the "deintermediation" of traditional intermediaries and transaction settlement systems, improve transaction efficiency, and reduce transaction costs.

The traditional agricultural supply chain is a distributed network chain structure composed of enterprises, farmers, distributors, regulators, consumers, and other participating entities. Due to the characteristics of agriculture, the participants of agricultural supply chain are distributed in space and time dimension, and the traditional centralized transaction structure can easily add the cost of information processing and the degree of information asymmetry, resulting in higher transaction costs. The distributed and decentralized characteristics of blockchain are coupled with the distributed network organization of agricultural product supply chain. The agricultural product supply chain embedded in the blockchain can use the point-to-point information and value transmission network architecture based on the blockchain P2P network to trade, thereby changing the centralized governance of agricultural product supply chain governance. Blockchain technology embedding can transform the original "series" organizational governance structure of agricultural product supply chain into a flat "parallel" organizational governance structure. The participants can realize the direct exchange of economic factors in the agricultural product supply chain system based on blockchain and form the technical support of "deintermediation" in the agricultural product supply chain organization, thus further reducing the transaction cost.

The governance of agricultural product supply chain includes complex contents, such as the docking of external market transactions, the collaboration among organizational members, and the hierarchical governance within members. The blockchain can be divided into public chain, alliance chain, and private chain according to the degree of openness. Public chain refers to the blockchain where anyone can join, read data, participate in the consensus process, send transactions, and obtain effective confirmation at any time; alliance chain refers to the blockchain where consensus process is controlled by preselected nodes, allowing only designated node users to account for and modify blockchain data, which can be regarded as a "partially decentralize" blockchain; private chain refers to the blockchain that the written permissions are controlled by an organization or institution, whose data processing speed is far better than 


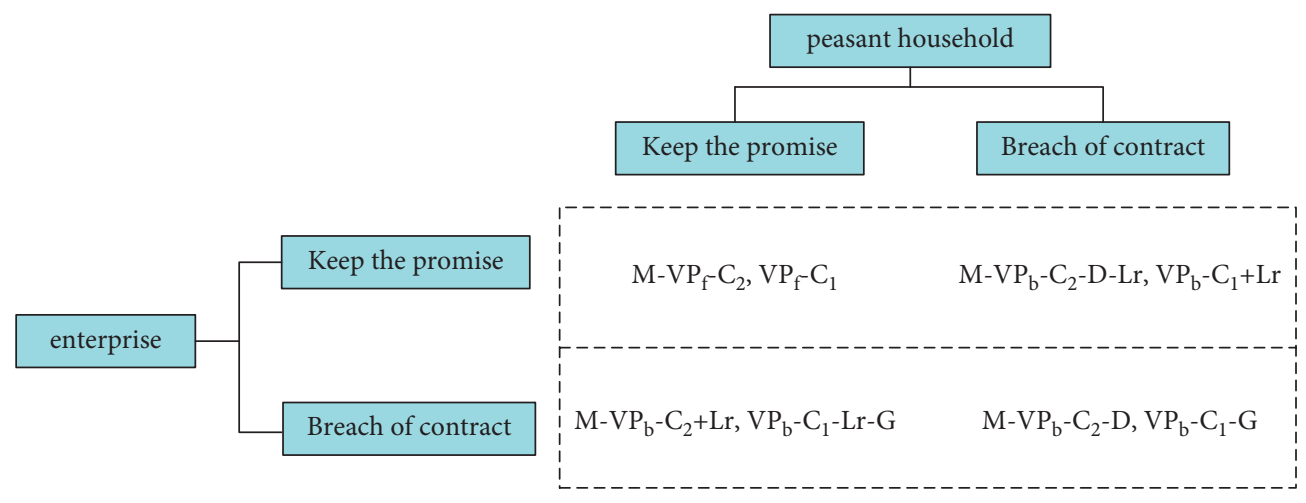

FIGURE 6: Income of companies and intermediary organizations when market development is poor.

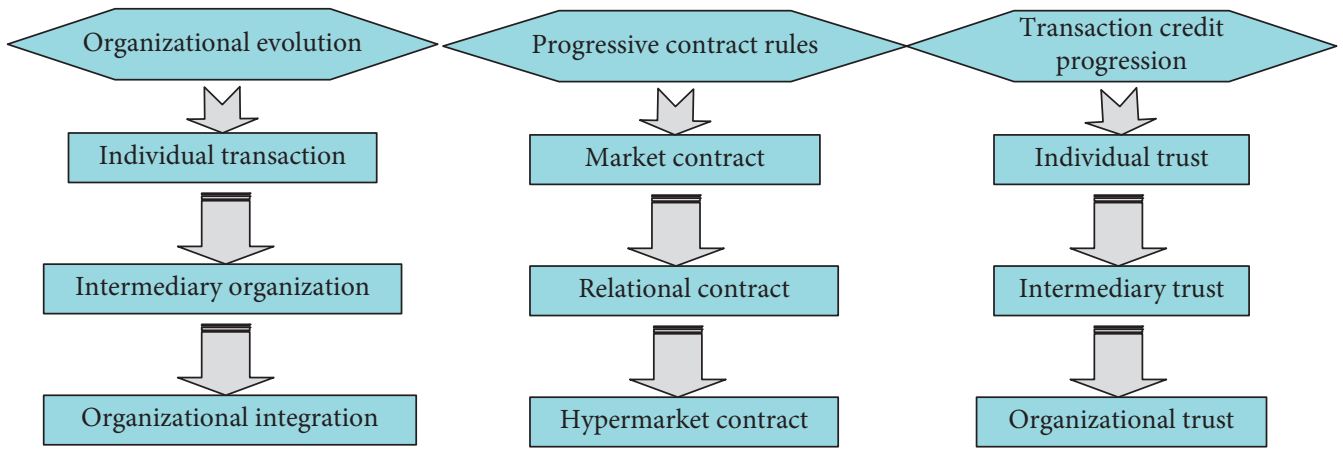

FIGURE 7: Evolution of organizational governance of agricultural supply chain.

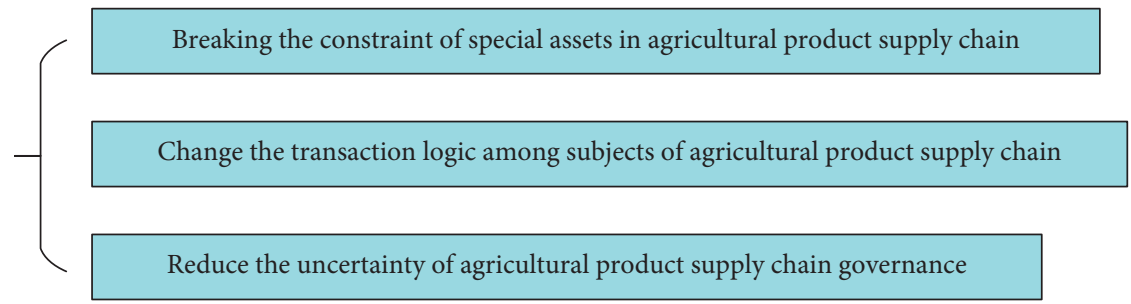

FIGURE 8: Blockchain embeddedness affects three important factors of agricultural supply chain governance.

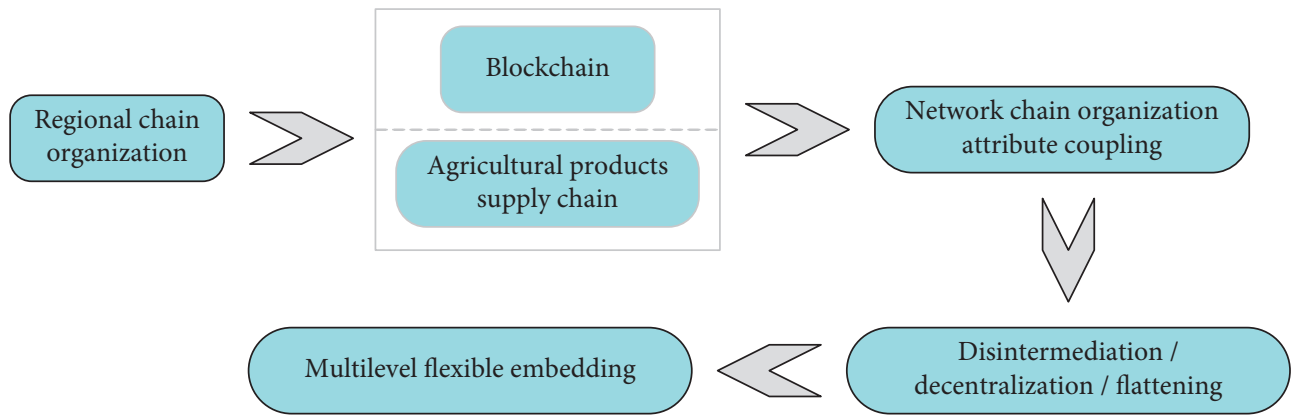

FIGURE 9: Blockchain optimizing the organization structure of agricultural products supply chain network chain.

public chain and alliance chain. Considering the processing speed and the privacy of book access, many enterprises choose private chain technology at the level of corporate governance. Agricultural products supply chain can flexibly use cross-chain, public chain, alliance chain, private chain, hierarchical cloud mechanism, and other technologies to deal with the participants of agricultural products supply chain dynamically and form a more matching blockchain and the network chain coupling mapping of agricultural products supply chain. 
3.3.2. Blockchain Improves the Contract Completeness of Supply Chain of Agricultural Products. When constructing the contract theory, the relevant scholars found that there were some differences in the information about the quality and sales volume of agricultural products owned by both parties to the contract, and, in the whole process of transactions between both parties, irrational transactions might occur between both parties. Therefore, it is very difficult to clarify all the rights and obligations that both parties need to perform when conducting transactions through the clauses in the contract, and this will increase transaction costs $[23,24]$. Therefore, incomplete contracts are ubiquitous in the transaction process of both parties, and the main transaction costs brought by incomplete contracts include the three following points: First, because there are relatively many trading subjects involved in the supply chain of agricultural products, the cost of signing contracts is relatively high. Second, because there are few "objects" contents to be standardized when the subject of agricultural products trade enters into a contract, the cost to supervise the implementation of the contract is higher than the trading target of agricultural products. Third, natural disasters and market risks will have a great impact on the production of agricultural products, and both natural disasters and market risks have unpredictability, resulting in higher information and cognitive costs [25].

Incomplete contracts and transaction costs are the sources of organizational and governance problems, while a considerable number of scholars believe that, when solving the problems caused by incomplete contracts, a new generation of technologies such as blockchain can be embedded. Figure 10 explains the specific structure.

\subsubsection{Blockchain Optimizes Organizational Trust of Supply} Chain of Agricultural Products. The root cause of the breach of contract between the two parties is not the incomplete contract but the speculative behavior. Companies, farmers, intermediary organizations, and other participants in the supply chain of agricultural products may realize their own goals by relying on other parties violating the rules in order to realize their own interests in the transaction process, and the stronger the asset specificity is in the supply chain of agricultural products, the more likely the trading subject is to be "locked up," and the more likely it is to have speculative behavior.

All the problems in the supply chain of agricultural products, such as high uncertainty, speculative behavior, and limited rationality of trading subjects, will lead to the emergence of organizational and governance problems. An effective way to overcome speculative behavior and enable the trading subjects to cooperate for a long time is to improve the trust of both parties. Interpersonal trust can solve problems such as difficulty in quantifying transaction costs and unclear property rights in supply chain of agricultural products caused by incomplete contracts.

Blockchain based on digital technology can not only make the transaction information transparent but also make it automatically execute the contract contents through intelligent contracts, to avoid the speculative behavior that the transaction subjects improve their own interests by deception in the transaction process. Figure 11 shows the specific structure.

\subsubsection{The Principle of the Agricultural Product Supply Chain} Governance. Agricultural product supply chain governance is a very interdisciplinary subject, which can be divided into aspects of agricultural products, supply chain, and governance. Different combinations, different perspectives, and different focuses of the three aspects influence each other, infuse with each other, and then derive the ever-changing researches and results. From the perspective of agricultural products, the different biochemical characteristics of agricultural products, regional agricultural production, farmers' different preferences, and cultural attributes of different aspects of the change factors into the subject of agricultural supply chain governance will form a new perspective of research. Therefore, with the deepening of research, scholars' researches show gradually more specific trends, such as focusing on the supply chain management of some agricultural products, comparative analysis of supply chain management of different agricultural products, the impact of agricultural production brought by regional characteristics on the supply chain management of agricultural products, and the impact of farmers' various preferences on the supply chain management of agricultural products, and these studies show different research results through different research methods and models. In the past few decades, with the development of globalization, industrialization, and technology, supply chain has experienced multiple stages of development, including logistics management stage, value-added stage, network chain stage, and emerging supply chain business stage, and both its external form and internal mechanism have undergone great changes. From the perspectives of supply chain logistics, capital flow, and information flow, the research on agricultural product supply chain governance derives many research topics such as agricultural product supply chain finance, agricultural product quality and safety governance, and information sharing under agricultural product supply chain. From the perspective of governance, researches are more consistent with the development logic of new institutional economics. With the continuous enrichment of the content of new institutional economics, the research contents, and achievements of agricultural product supply chain organization, contract regulation and relationship governance are also constantly enriched.

\section{Results and Discussion}

4.1. Analysis of China's Total Output Value and Total Import and Export Volume of Agricultural Products. As a big agricultural producer, China's gross agricultural output value has exceeded the trillion yuan mark at the end of last century. With the steady growth of gross agricultural output 


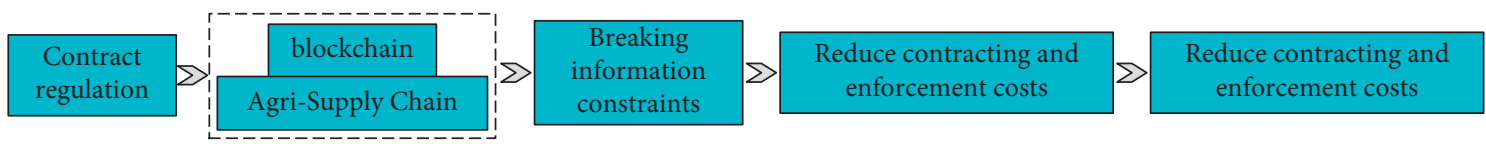

Figure 10: Blockchain optimizing contract regulation of supply chain of agricultural products.

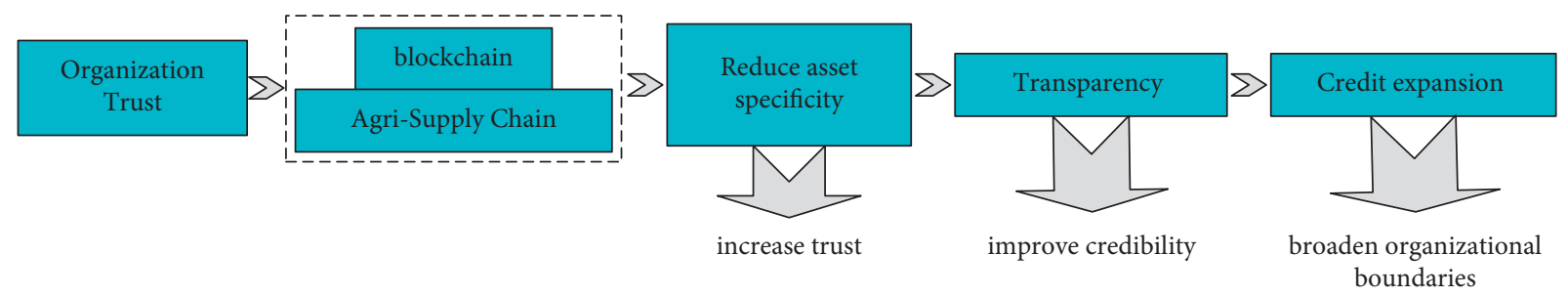

FIGURE 11: Blockchain strengthening organizational trust in agricultural supply chain.

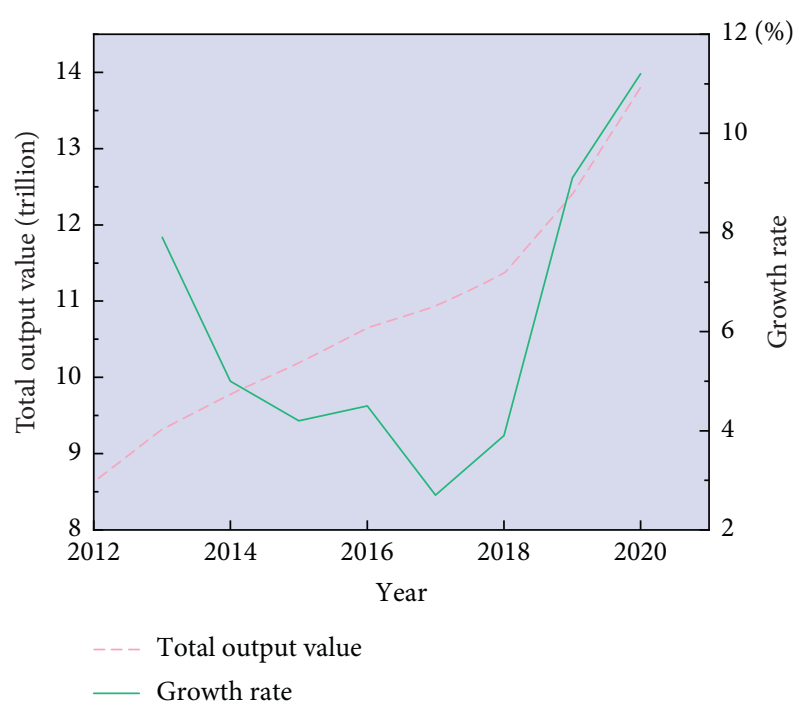

Figure 12: Gross output value and growth rate of agricultural products in China from 2012 to 2020.

value, China's agricultural production and management level are also steadily improving. Figure 12 presents the total output value and growth rate of China's agricultural products in recent years.

As Figure 12 shows, China's gross agricultural products have been increasing since 2012, with the gross agricultural products of China reaching 11.36 trillion yuan in 2018 and 12.4 trillion yuan in 2019, up 9.1\% year-on-year. China, as an important global producer and consumer of agricultural products, has increased the proportion of agricultural products trade in the world agricultural products trade year by year. It is playing an increasingly important role in the world's agricultural trade. With the rapid growth, the structure of China's agricultural trade is constantly changing as shown in Figure 13.

Figure 13 describes that the total of import and export of agricultural products in China showed a declining trend from 2014 to 2017. From 2017, the total of import and export of agricultural products in China began to rise continuously. In 2018, the total of import and export of agricultural products was $\$ 228.43$ billion, and, in 2019 , it was $\$ 228.43$ billion, an increase of $5.7 \%$ year-on-year.
4.2. Functional Framework of Supply Chain Governance of Agricultural Products under the Blockchain Technology Path. In the process of rapid development of digital technology, blockchain technology has been continuously integrated with digital technology to provide more effective solutions for optimizing the organizational governance system. By combining different digital technologies, different technical characteristics can be brought to blockchain products. However, each blockchain product can be divided into data layer, network layer, consensus layer, contract layer, and application layer on the technical path of systematic functional architecture. On the basis of consulting relevant literature, the overall functional framework of agricultural products supply chain is reconstructed in view of the existing problems in the current supply chain of agricultural products, which can be divided into five parts as shown in Figure 14.

In order to intelligently identify and track and monitor the processes and subjects in the supply chain of agricultural products, the physical layer in Figure 14 is set up, which includes various digital technologies such as intelligent remote sensing and laser scanning. Through the integration with these technologies, the planting, processing, and logistics information in the supply chain of agricultural products can be collected. For example, if the sensor is installed on the agricultural seed machine, the position information provided by GPS can be used to photograph the growth of farmland crops, which can be input into the computer system for further processing and storage of relevant data.

The data layer mainly includes many data technologies such as asymmetric encryption, hash function, and Merkle tree to store the data in the process of agricultural supply chain governance. Asymmetric encryption can encrypt data through a pair of public key and private key; the public key is open to the whole network, while the private key can only be used by individuals. This method can not only protect personal data privacy and ensure the information stored by users safely but also clarify the boundaries between the two parties in the supply chain. Hash function has the characteristics of noninterference and being one-way. Based on these characteristics, it can ensure that the data in the supply chain of agricultural products will not be easily tampered 


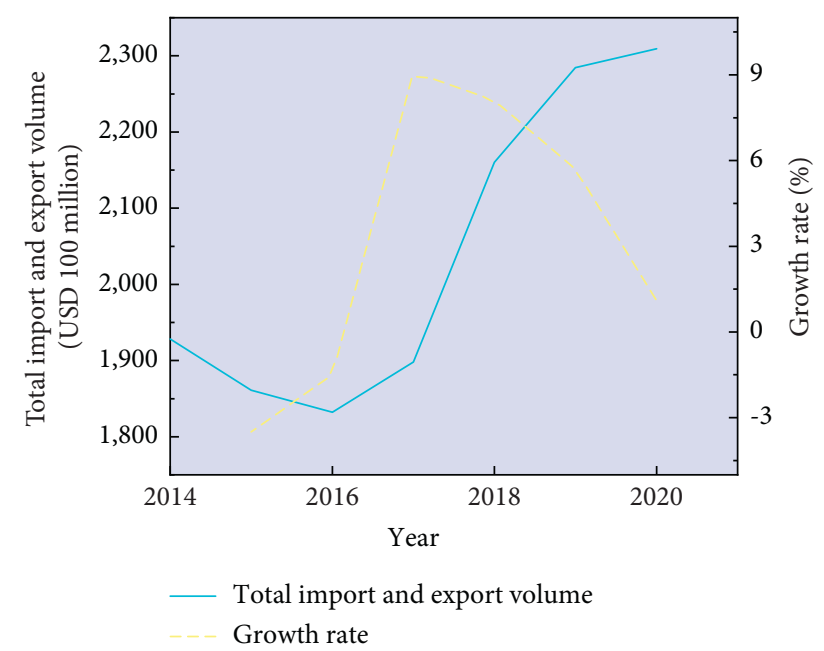

FIGURE 13: Total of import and export volume and growth rate of China's agricultural products from 2014 to 2020.

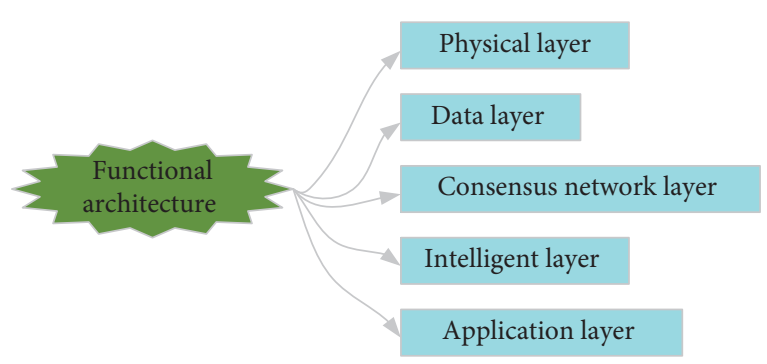

FIgURE 14: The overall functional framework of supply chain governance of agricultural products.

and ensure the authenticity of the recorded data. Merkle tree is an essential technology when building the block data structure of blockchain. Its branch nodes can store the calculated hash value, and the root value corresponds to the last hash value in recursive calculation, which is recorded in the block data structure together to ensure that the previous data can be traced back. Therefore, this technology can be used when constructing the data traceability system of supply chain of agricultural products and building the relational database based on the trading network.

The consensus network layer includes cross-chain technology for connecting different blockchains, consensus algorithms such as DPoS and PoW, and P2P network technology. The network layer frames the data verification structure, information dissemination mechanism, and network formation mode among the trading subjects of supply chain of agricultural products and reshapes the organization mode of supply chain of agricultural products. Among them, DPoS, PoW, and other blockchain consensus algorithms can ensure that the number of general ledgers is consistent when the bookkeeping rights of each node in the supply chain of agricultural products organization are the same. The distributed ledger formed based on this algorithm can improve the trust between transaction subjects and make the organizations in the supply chain of agricultural products form mutual trust. P2P network technology can ensure that the trading statuses of each subject equal each other in supply chain of agricultural products. In this case, the intervention of third-party intermediary is not needed, and the point-topoint trading structure among trading subjects is realized, thus effectively reducing the transaction cost.

Intelligent contract layer includes Multisignature Technology, Programmable Script Technology, and Turing Complete Technology. It can transform contracts in supply chain of agricultural products into computer protocols in blockchain data structure through program codes. This protocol adopts self-verification method and automatically performs tasks without intervention of intermediary. In order to make the information exchange, asset management, and value transfer between trading entities more efficient and convenient, various data and assets can be flexibly embedded in smart contracts. It can also be embedded with intelligent prediction machines and various intelligent algorithms involved in transactions to build an intelligent system that can analyze the environment and make corresponding decisions.

The application layer contains various application cases and scenarios in the supply chain of agricultural products, which are applied to the specific production process based on the functions of the above layers. For example, the organizational credit system of supply chain of agricultural products is constructed, and the data of the participants' demand and financial supply are analyzed. Through the above analysis, the intelligent functional framework of agricultural products supply chain based on blockchain can be obtained as in Figure 15.

4.3. Mechanism Optimization of Supply Chain Governance of Agricultural Products under Blockchain Technology Path. All participants in the supply chain of agricultural products can sign contracts before trading, so that the interests of both parties can be effectively guaranteed. The clearer the terms in the contracts, the more stable the cooperative relationship between both parties. At present, the commonly used formal governance mechanism is shown in Figure 16.

In the governance mechanism of agricultural supply chain, it includes not only formal governance mechanisms such as contracts but also informal governance mechanisms such as agreements and exchanges, as shown in Figure 17.

\subsubsection{Blockchain Embedding Optimizes the Trust Mechanism} of Supply Chain of Agricultural Products. Because the supply chain of agricultural products is greatly influenced by the natural environment, the investment risk is high, the establishment of trust relationship between trading subjects can avoid opportunistic behavior to a great extent, and the improvement of trust between trading subjects can improve the stability of the supply chain of agricultural products. By encrypting and transparentizing the data and information, the distrustful factors in the blockchain can be removed, and the influence degree of the organization can be reduced by "information without doubt." Blockchain can encrypt data information to ensure the authenticity and reliability of data and reduce the influence of personal feelings on trust. In order to effectively deal with the limited rationality among 


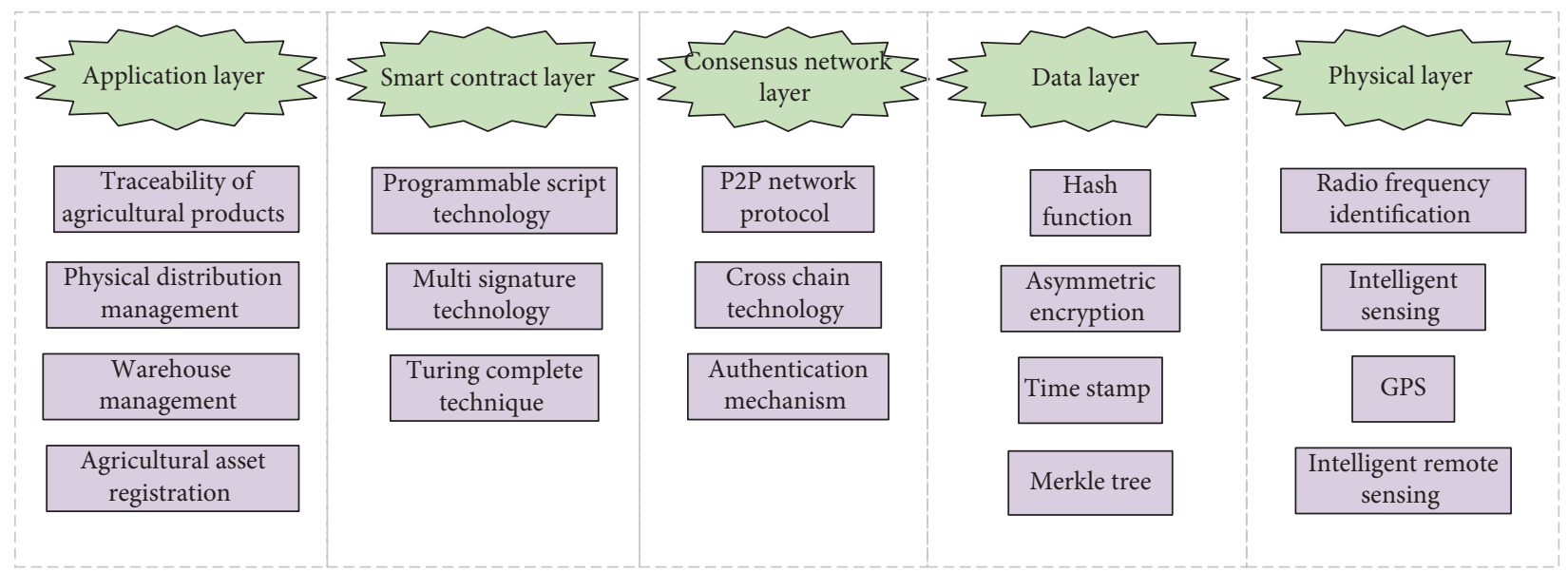

FIGURE 15: Functional framework of supply chain governance of agricultural products based on blockchain.

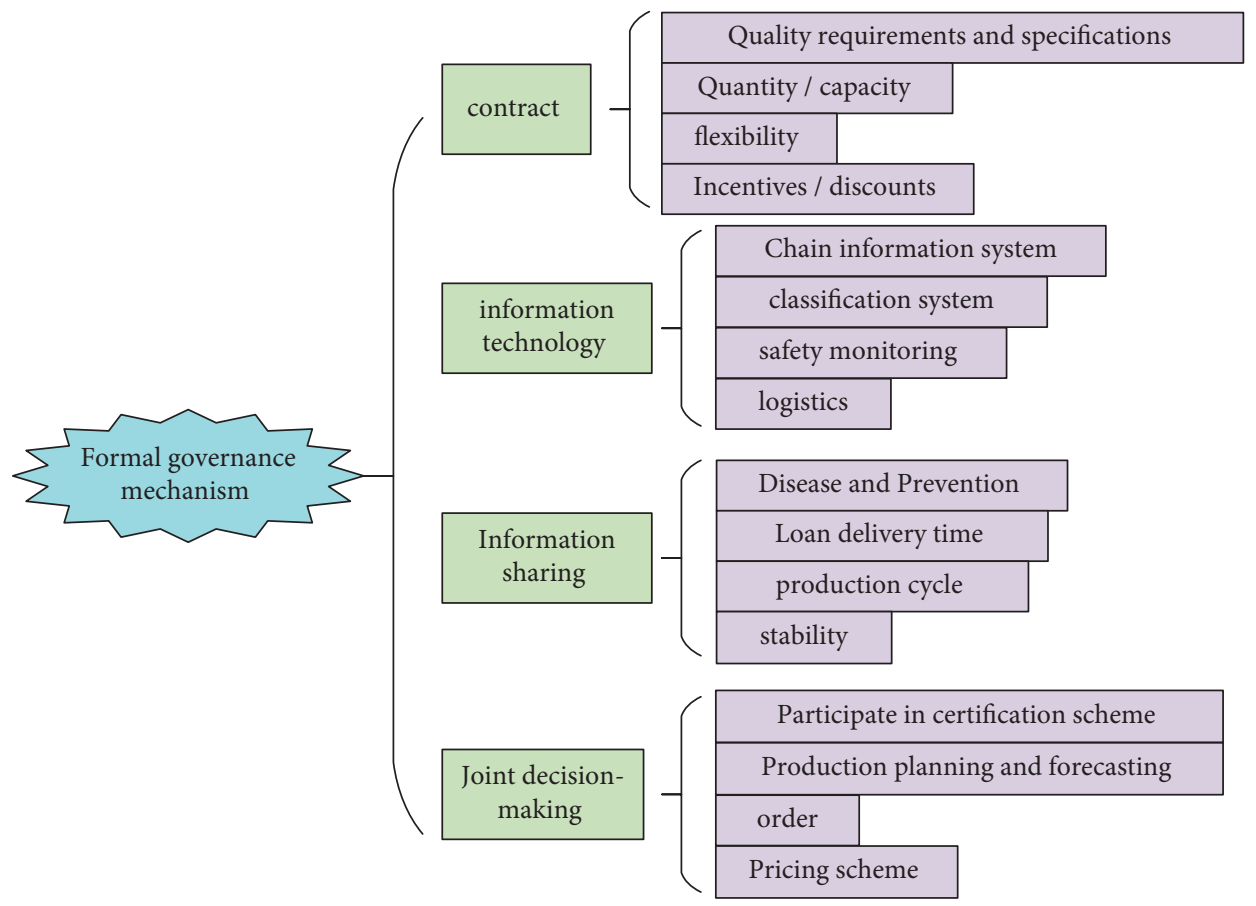

FIGURE 16: Formal governance mechanism of supply chain of agricultural products.

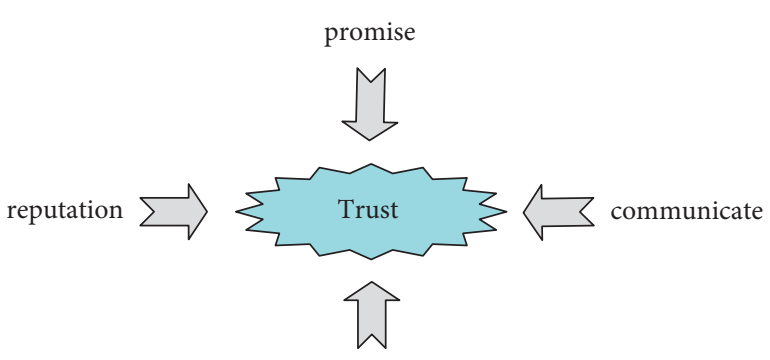

Relationship asset investment

FIGURE 17: Informal governance mechanism of supply chain agricultural products.

the trading subjects, there are two main ways to realize "information without doubt" based on the technology of blockchain: first, construct the infrastructure of "information without doubt" based on new information technology; second, build the digital trust mechanism to improve the enthusiasm of trading subjects such as companies, farmers, and intermediary organizations.

Figure 18 signifies the "information without doubt" technology constructed according to the above contents.

4.3.2. Blockchain Optimizes the Contract Mechanism of Agricultural Supply Chain Governance. Contract mechanism is similar to smart contract, which is realized by computer programming. Based on reducing costs, its application scope is broader, and the transparency of the implementation process greatly reduces the probability of default by both parties. The smart contract based on blockchain technology can be divided into broad sense and narrow sense. The broad sense smart 


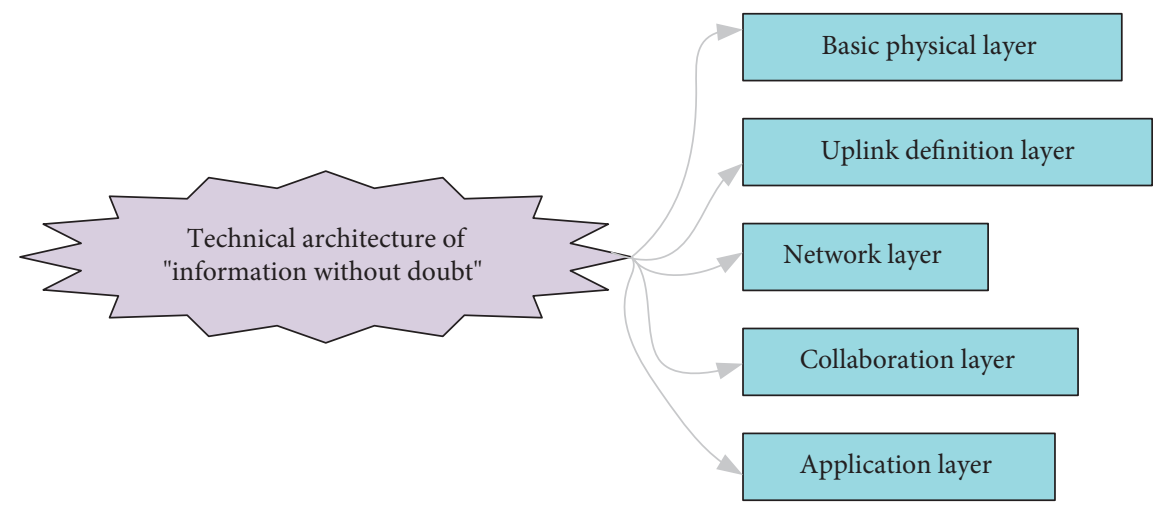

FIGURE 18: Technical architecture of “information without doubt." In addition, the application of blockchain technology can optimize the trust generation and guarantee mechanism in supply chain of agricultural products, illustrated in Figure 19.

contract does not consider the influence of intermediary organizations. It can consciously carry out relevant activities according to the contents of the contract and play a supplementary or even alternative role to the existing rules and regulations.

In the supply chain of agricultural products based on blockchain technology, transactions among companies, intermediary organizations, farmers, and other trading entities can be transformed into codes by computer algorithms and then evolved into programs, forming computer protocols and storing them. Economic activities such as identity authentication and contract transactions can be completed through intelligent contracts. Figure 20 shows the specific functional architecture.

\subsection{Case Analysis}

4.4.1. Case Description. Based on the high-quality black land of "BEIDAHUANG Group," "Shan Liang Taste" integrates a new generation of information technologies such as Internet of Things, blockchain, and big data to serve the whole supply chain and creates the first rice supply chain system in China based on blockchain in the form of "consumers + logistics system + trading platform + production base + farmers." "Shan Liang Taste" implements the digitization of agricultural assets. The supply chain is split into 1639 business nodes, spanning 3 farms, 9 administration areas, and 33 workstations, signing 249 plots (a total of $24318.98 \mathrm{mu}$ ), and covering 1477 plots (a total of $271223.03 \mathrm{mu}$ ), and single land has 17 conventional digital attributes. "Shan Liang Taste" links the contracted agricultural land to the network platform, forming the corresponding programmable assets. Relying on the modernized, standardized, and mechanized production management mode of the "BEIDAHUANG Group," various intelligent devices are embedded in all aspects of the supply chain such as rice planting, production, sales, and after-sales. Collection is made on a series of data such as soil environment, fertilizer and water use, seedling information, rice deep processing, storage and transportation, and sales and distribution in the process of rice planting. After process screening and algorithm screening, the data are uploaded to the blockchain to ensure the objective authenticity of the data.
Based on this, "Shan Liang Taste" realizes the comprehensive data mapping of the participants, production, and circulation, agricultural assets, and trading system of the rice supply chain in the blockchain network, breaks the data island, and forms the consistent database of the rice supply chain based on the blockchain. Specifically, "Shan Liang Taste" uses blockchain to create a closed-loop autonomous system and develops APP and digital equipment based on blockchain in the production and logistics links of rice supply chain for digital governance.

In the transaction of rice supply chain, on the one hand, "Shan Liang Taste" makes the best of the financial and technological characteristics of blockchain to organically combine the circulation of digital assets of farm land with bulk grain transactions. In the blockchain environment, "Shan Liang Taste" forms a confirmed agricultural product by anchoring with the land of "Shan Liang Farm," thus creating a brand grain futures trading scene based on blockchain "Grain Exchange." "Shan Liang Taste" anchors the digital assets of agricultural land with the "Shan Liang blockchain grain ticket," a tradeable and mortgageable digital planting order produced by the plot. Grain ticket is the only certificate for grain physical delivery in "Grain Exchange," and farmland asset securitization is completed by anchoring grain ticket and real grain.

On the other hand, "Shan Liang Taste" implements e-commerce sales for consumers. Consumers can delimit a part of the farm through cloud farms, order one season of rice produced on the land, and generate orders online with one button. Farmers can contract the production orders of land anchored by "Shan Liang Blockchain Grain Ticket" online through "Farmer Treasure," thus forming blockchain futures products of shared farms. After that, through the closed-loop channel construction and traceability certification process of "Shan Liang Taste," the high-quality grain with "geographical stamp, time stamp, and quality stamp" is sent to consumers by express delivery. In June 2018, "Shan Liang Taste" cooperated with Tencent and issued a "Shan Liang Blockchain Order" corresponding to the land through WeChat, which was sold online at the price of CNY 8,000 per $\mathrm{mu}$ of land and $500 \mathrm{~kg}$ of high-quality rice to support online crowdfunding consumption. Ten people could make group reservations and the goods would be delivered by express 


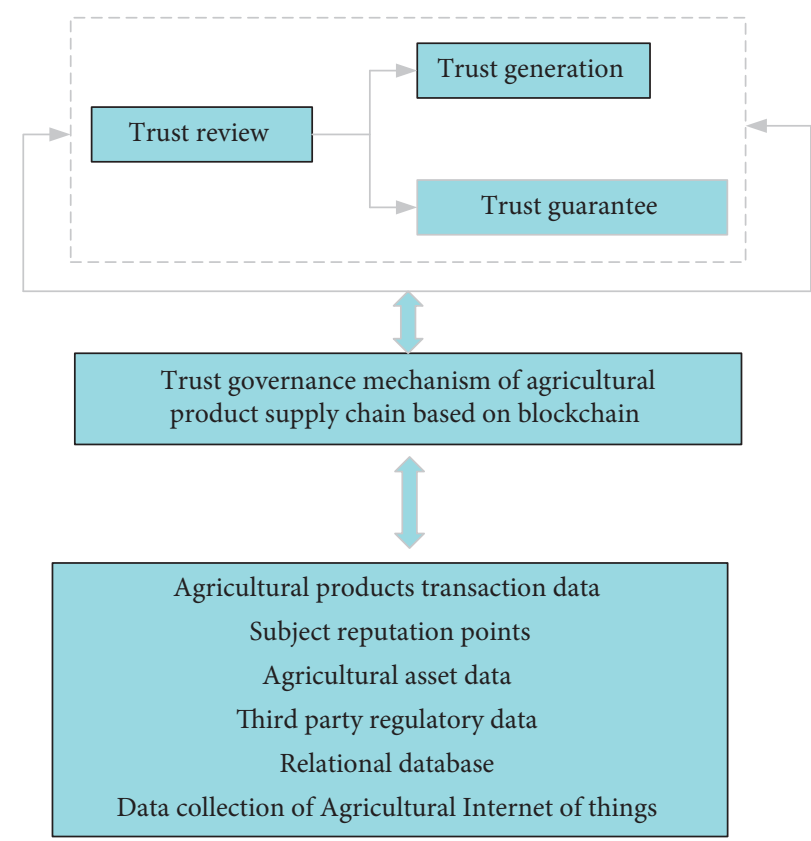

FIGURE 19: Trust mechanism structure of supply chain of agricultural products based on blockchain.

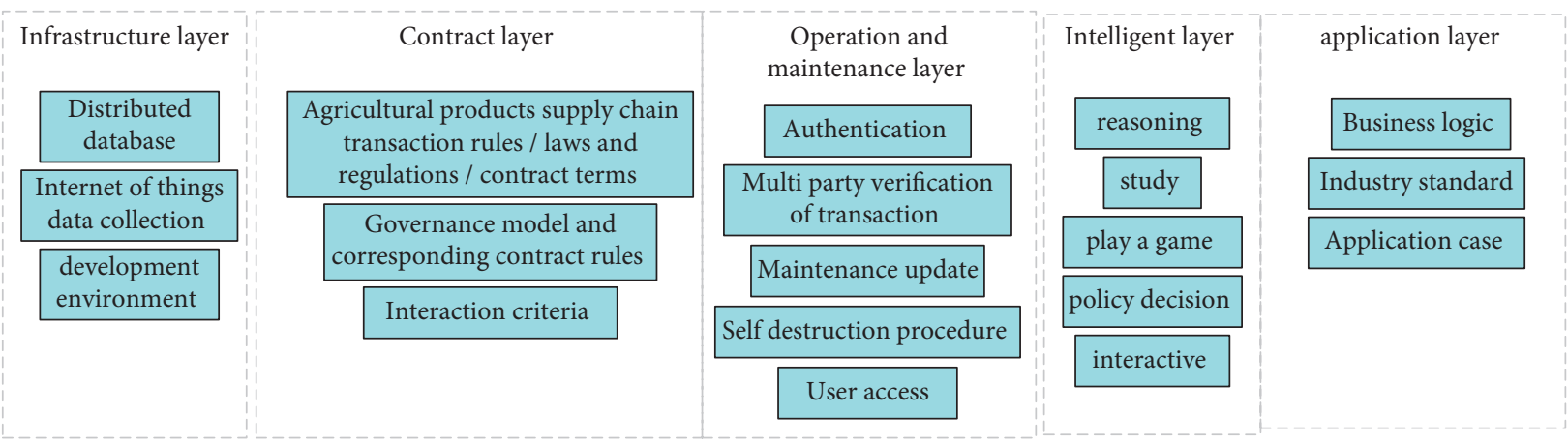

FIGURE 20: Functional architecture of intelligent contract mechanism of supply chain of agricultural products based on blockchain.

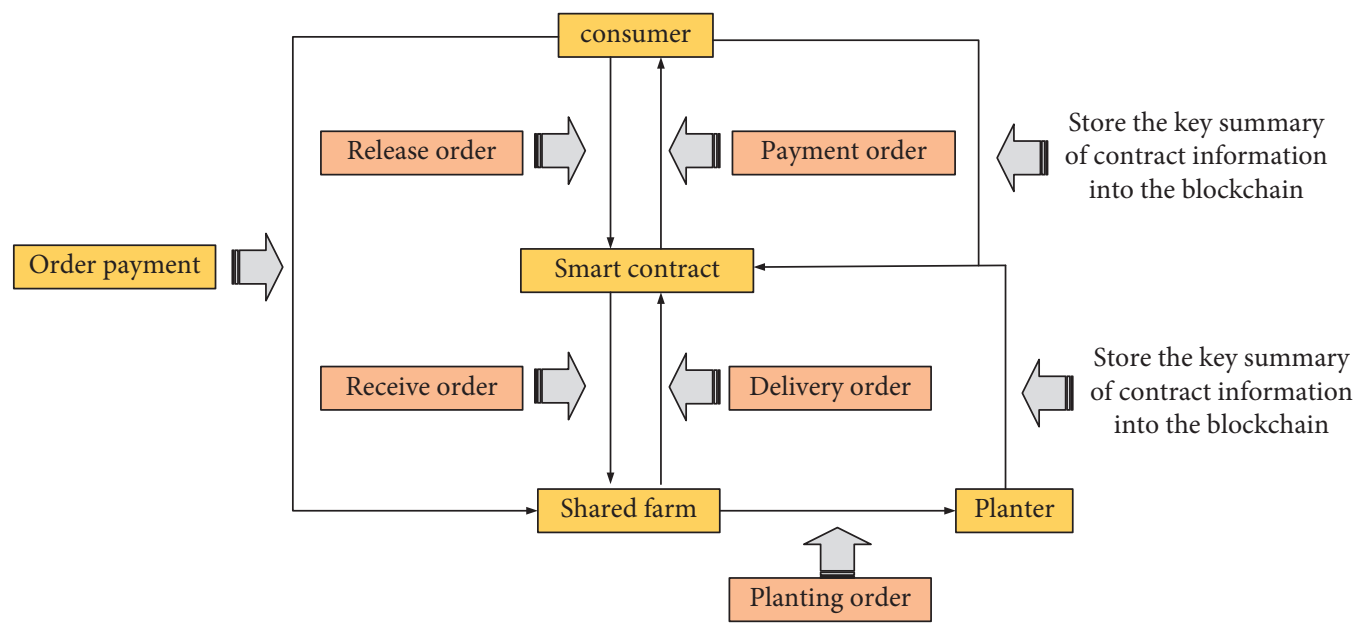

FIgURE 21: Ordering flow of "Shan Liang Taste Sharing Farm." 


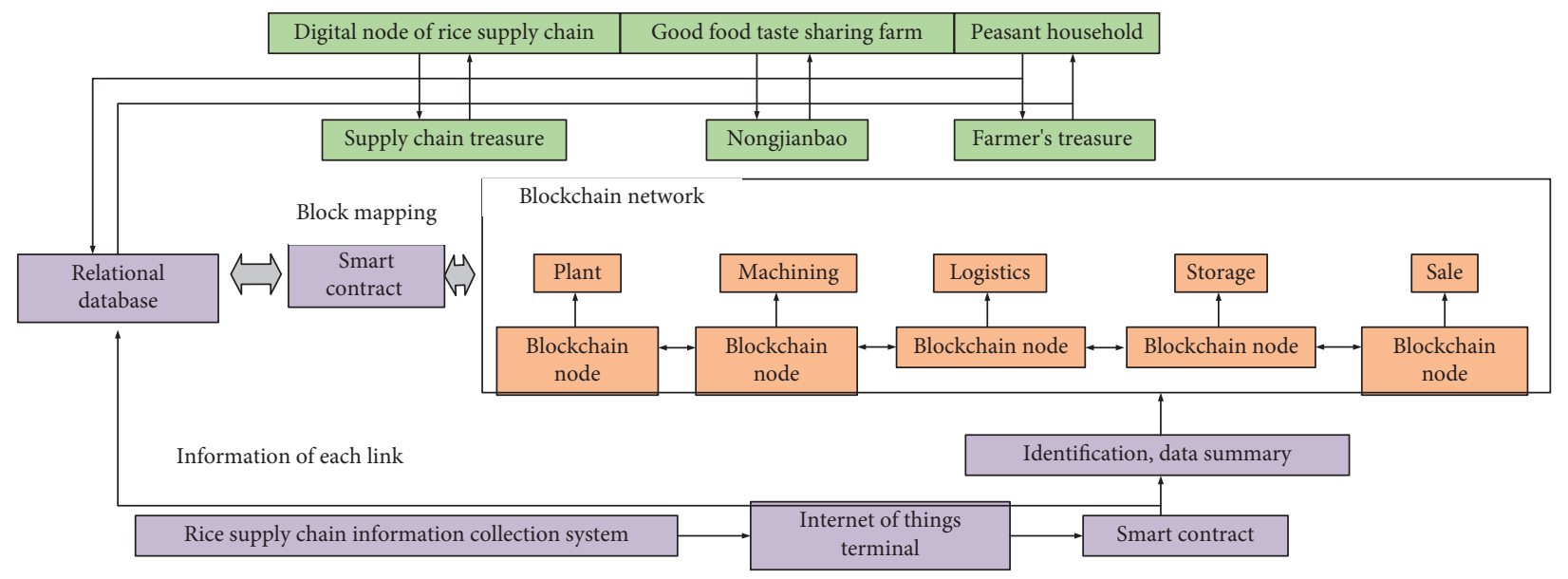

FIgURE 22: Scheme of the "Shan Liang Taste" blockchain network architecture.

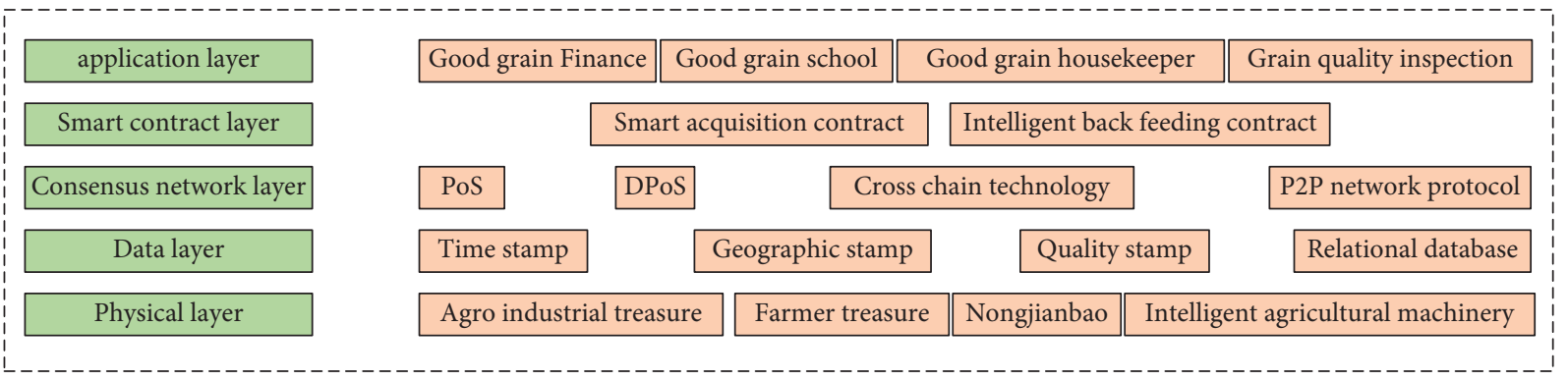

FIGURE 23: System functional framework based on blockchain governance for "Shan Liang Taste."

delivery four months later. Figure 21 illustrates the ordering flow of "Shan Liang Taste Sharing Farm."

Whether it is the blockchain-based commodity trading or consumer-oriented online orders, "Shan Liang Taste" uses blockchain-based smart contracts. "Shan Liang Taste" digitizes and programmes the order through script code. Once the system triggers the threshold, the contract terms will be automatically executed, and none of participants of the contract unilaterally have right to cancel or prevent the contract execution, which effectively solves the contract credit problem faced by the original rice supply chain. "Shan Liang Taste" releases the rights, responsibilities, and benefits of all aspects of the agricultural supply chain transparently and open in the form of blockchain-based smart contract terms. Once an order happens in the sales end, intelligent contracts will automatically allocate revenue to each supply chain link. The rice supply chain based on blockchain has formed a systematic, digital, and intelligent benefit distribution mechanism. The originally fragmented supply chain subjects have formed efficient coordination and positive incentives through algorithms.

"Shan Liang Taste" relies on a new generation of information technology to create a variety of integrated applications for specific scenarios of rice supply chain at the platform level, for example, relying on BEIDAHUANG Group standardized production, integrated services, and digital management to create "Shan Liang Stewards," to provide integrated services for supply chain participants, unified breeding, agricultural procurement, production planning, warehousing acquisitions, logistics, and distribution services; developing "Shan Liang School" to spread farming skills and knowledge and providing all-round skills services such as fertilizer and pesticide use and pest control technology for the new farmers who contracted rice production tasks; cooperating with financial institutions to create "Shan Liang New Finance" and forming a consistent database based on blockchain with financial institutions. Based on the big data analysis of the production, processing, logistics, trading, and consumption of the rice supply chain, financial services such as borrowing, asset securitization, and insurance are carried out to solve the problems of opaque financial information in the agricultural supply chain, redundant intermediaries, and complex business processes and provide effective protection for the financial needs of farmers and SMEs in the rice supply chain. Figure 22 demonstrates the scheme of the "Shan Liang Taste" blockchain network architecture.

4.4.2. Optimization of Agricultural Products Supply Chain Governance from the Perspective of Blockchain Embedding. Blockchain is the technology to solve the problem of rice supply chain. Besides, the underlying technical logic of decentralization, trust, intelligent contract, and consensus sharing of blockchain is the core of guiding the project of "Shan Liang Taste." "Shan Liang Taste" uses blockchain as the underlying functional architecture to integrate Internet of Things, big data, artificial intelligence, visualization, and 
other technologies into the framework to optimize the governance of rice supply chain. According to the functional framework design of agricultural product supply chain governance based on blockchain, "Shan Liang Taste" also adopts similar functional architecture on the technical path: basic physical layer, data layer, consensus network layer, intelligent contract layer, and application layer.

The basic physical layer integrates technologies such as the Internet of Things, mobile Internet, big data, remote control, and data processing. Each node in the rice supply chain contains much data. These data are collected through various technologies and terminals in the physical layer and uploaded to the system with communication protocols. The whole process mapping of the rice supply chain is completed in the physical layer. "Shan Liang Taste" relies on the same cultivation of rice standard with BEIDAHUANG Group and uses the Internet of Things, mobile Internet, and other technologies to realize the whole process of data collection in the preparation, production, and receiving links. The data layer integrates hash function, distributed database technology, timestamp, cloud database, Merkle tree, and other technologies to receive data from the basic physical layer and unify data format, which is stored in the "Shan Liang Taste" system. The consensus network layer adopts the common consensus algorithms such as PoS and DPoS and the hybrid consensus mechanism of joint consensus. The intelligent contract layer encapsulates the business logic and transaction logic of the code-programmed "Shan Liang Taste" system, which is a complete intelligent contract. The application layer encapsulates the application logic of specific cases in the "Shan Liang Taste" rice supply chain based on the functions of each layer. The API interface provided by the underlying blockchain can call the distributed data of each layer and the resources for consumers, enterprises, regulators, and trusted service providers to realize the governance requirements of specific system applications, such as user authentication, quality inspection and detection, product traceability, monitoring and early warning, supply chain finance, and other specific application scenarios. Figure 23 signifies the system functional framework based on blockchain governance for "Shan Liang Taste."

\section{Conclusion}

Because the information owned by the trading subjects in the agricultural supply chain is not completely consistent and not necessarily completely rational in the trading process, there is instability in the governance of the agricultural supply chain, which will lead to speculative behavior of the trading subjects. According to the new institutional economics theory of blockchain technology and agricultural supply chain governance, the governance of supply chain of agricultural products is discussed through literature research, executive analysis, and interdisciplinary research. The results are as follows: By analyzing the organizational structure and stability of two organizational models, "company and farmer" and "company, intermediary organization, and farmer," a deep discussion is made on the relationship, organizational structure, and manifestation of trading subjects in the supply chain of agricultural products. With the rapid development of the new generation of information technology, such as blockchain, Internet of Things, and computer technology, it is possible to comprehensively digitize economic activities such as production and transaction in the supply chain of agricultural products.

\section{Data Availability}

The labeled datasets used to support the findings of this study are available from the corresponding author upon request.

\section{Conflicts of Interest}

The authors declare no conflicts of interest.

\section{Acknowledgments}

This work was supported by the project of Education Science Planning in Anhui Province, the Research on the Talent Training and the Countermeasures of Higher Vocational Education in Connection with Agricultural Modernization, under JG14016, and Key Research Project of Humanities and Social Sciences of Anhui Provincial Department of Education, Research on the Transformation and Development of China's Retail Industry under the New Retail Normal, under SK2016A0353.

\section{References}

[1] S. Cheng and M. López, "Synergy analysis of agricultural economic cycle fluctuation based on ant colony algorithm," Open Physics, vol. 16, no. 1, pp. 978-988, 2018.

[2] X. He, L. Dong, J. Huang, and K. Hu, "Agricultural climate change and agricultural economic sustainability based on resource scheduling algorithm," Arabian Journal of Geosciences, vol. 14, no. 15, pp. 1-19, 2021.

[3] J. Gao, "Two echelon supply chain model of agricultural products based on stochastic fuzzy process of cost demand," International Journal of Reasoning-Based Intelligent Systems, vol. 9, no. 3-4, pp. 149-156, 2017.

[4] U. S. Sakalli, "Optimization of production-distribution problem in supply chain management under stochastic and fuzzy uncertainties," Mathematical Problems in Engineering, vol. 2017, no. 10, pp. 1-29, 2017.

[5] X. Chen and Y. Yun, "Optimization of a green supply chain network with various transportation types for tire industry in korea," Journal of the Korean Society of Supply Chain Management, vol. 19, no. 2, pp. 91-106, 2019.

[6] D. Delfitriani, "A supply chain risk management for dadih product by pricing optimization," SEAS (Sustainable Environment Agricultural Science), vol. 2, no. 1, p. 41, 2018.

[7] J. Zhao, K. Gerasimova, Y. Peng, and J. Sheng, "Information asymmetry, third party certification and the integration of organic food value chain in China," China Agricultural Economic Review, vol. 12, no. 1, pp. 20-38, 2019.

[8] Y. Sun, X. Yuan, and K. Shi, "Research on decision of supply chain of fresh agricultural products based on altruism preference," Systems Engineering-Theory \& Practice, vol. 37, no. 5, pp. 1243-1253, 2017. 
[9] Y. Li and C. J. Zhang, "Vertical Integration of Agricultural products supply chain and quality Safety of Agricultural products," E3S Web of Conferences, vol. 275, no. 4, p. 2048, 2021.

[10] W. Zhou and M. S. Metawea, "Quality safety of agricultural products in supply chain-computer simulation based on multi-agent system," Journal of Intelligent and Fuzzy Systems, vol. 5, no. 2, pp. 1-8, 2021.

[11] L. Qiu, "Research on RFID investment decision and coordination of fresh agricultural products supply chain based on fixed price," Revista de la Facultad de Ingenieria, vol. 32, no. 14, pp. 342-347, 2017.

[12] M. Muzammal, Q. Qu, and B. Nasrulin, "Renovating blockchain with distributed databases: an open source system," Future Generation Computer Systems, vol. 90, no. JAN, pp. 105-117, 2019.

[13] J. Thatcher, "Improving visibility and transparency with blockchain," APIC, vol. 27, no. 3, p. 16, 2017.

[14] L. Ismail, H. Materwala, and A. Hennebelle, "A scoping review of integrated blockchain-cloud $(\mathrm{BcC})$ architecture for healthcare: applications, challenges and solutions," Sensors, vol. 21, no. 11, p. 3753, 2021.

[15] M. S. Cheruvu, C. V. Cheruvu, and A. D. Farmer, "Oesophageal emergencies," Medicine, vol. 47, no. 4, pp. 224-227, 2019.

[16] Q. Li, X. Chen, and Y. Huang, "The stability and complexity analysis of a low-carbon supply chain considering fairness concern behavior and sales service," International Journal of Environmental Research and Public Health, vol. 16, no. 15, p. 2711, 2019.

[17] Z. Huang and L. Qiao, "Agricultural organizations and the role of farmer cooperatives in China since 1978: past and future," China Agricultural Economic Review, vol. 10, no. 1, p. 25, 2018.

[18] Y. Bo, X. H. Wu, Y. Bing, and Y.-W. Zhang, "Three-level supply chain coordination of fresh agricultural products in the Internet of Things," Industrial Management and Data Systems, vol. 117, no. 9, pp. 1842-1865, 2017.

[19] F. Özen, "On the intermediary effect of organizational policy: the effect of perceived ethical climate on corruption behavior of teachers," Journal of Education and Training Studies, vol. 6, no. 8, p. 52, 2018.

[20] J. Scholz, A. De Meyer, A. S. Marques et al., "Digital technologies for forest supply chain optimization: existing solutions and future trends," Environmental Management, vol. 62, no. 6, pp. 1108-1133, 2018.

[21] B. Yan, G. Liu, X. Wu, and J. Wu, "Decision-making on the supply chain of fresh agricultural products with two-period price and option contract," Asia Pacific Journal of Operational Research, vol. 38, no. 01, pp. 93-107, 2021.

[22] L. Popov and N. Yanneils, "Industrialization and the evolution of enforcement institutions," Economic Theory, vol. 69, no. 3, pp. 1-44, 2020.

[23] B. Lopez-Martin and D. Perez-Reyna, "Contracts, firm dynamics, and aggregate productivity," Journal of Economic Dynamics and Control, vol. 130, no. 3, p. 104190, 2021.

[24] J. Lehner and J. Sametinger, "Verwendung von Blockchain und Custom Tokens zur Projektkoordination - ein Pilot versuch," HMD Praxis der Wirtschaftsinformatik, vol. 55, no. 6, pp. 1285-1296, 2018.

[25] L. Song, X. Wang, P. Wei, Z. Lu, X. Wang, and N. Merveille, "Blockchain-based flexible double-chain architecture and performance optimization for better sustainability in agriculture," Computers, Materials \& Continua, vol. 68, no. 1, pp. 1429-1446, 2021. 